\title{
Primeiro Relato de Verrugose Negra Causada por Diplotheca tunae (Myriangiaceae) em Epiphyllum phyllanthus
}

\author{
Olinto L. Pereira \& Robert W. Barreto \\ Departamento de Fitopatologia, Universidade Federal de Viçosa, CEP 36571-000, \\ Viçosa, MG, e-mail: liparini@bol.com.br
}

(Aceito para publicação em 19/05/2006)

Autor para correspondência: Olinto L. Pereira

\begin{abstract}
First report of black scab caused by Diplotheca tunae (Myriangiaceae) on Epiphyllum phyllanthus

The fungus Diplotheca tunae, known to cause black scab on members of the family Cactaceae, is for the first time reported on Epiphyllum phyllanthus.
\end{abstract}

Epiphyllum phyllanthus (L.) Haw. é uma planta epífita, suculenta, desprovida de folhas, articulada, pertencente à família Cactaceae, de ocorrência em fragmentos remanescentes de mata atlântica (Lombardi \& Gonçalves, Revta Brasil. Bot. 23:255. 2000) e do cerrado brasileiro (Duringan et al., Plantas do cerrado paulista. 2004). Essa espécie é caracterizada por flores isoladas de coloração creme, com o hipanto muito longo, que só se abrem a noite, dando origem a uma baga ovóide, séssil, rosa-escura a magenta. Plantas de E. phyllanthus foram encontradas no sub-bosque da trilha da lagoa preta no Parque Estadual do Rio Doce (PERD) provenientes de galhos caídos após uma tempestade. Posteriormente, notou-se a presença de sintomas de verrugose na maioria dos caules coletados (Figura 1A). Porções mais jovens possuíam um número maior de verrugas, que inicialmente apresentam-se como pequenas pontuações escuras proeminentes, evoluindo para verrugas negras e protuberantes, comumente circundadas por um halo clorótico. O material foi encaminhado ao Laboratório de Micologia/Departamento de Fitopatologia/UFV e as estruturas do patógeno foram montadas em lactofenol ou lactofucsina. $\mathrm{O}$ fungo possuía as seguintes características morfológicas: lesões no caule com diâmetro de $0,3-7,0 \mathrm{~mm}$, restritas aos ascomas, de coloração negra; micélio interno intercelular, 2,5 - 3,0 $\mu \mathrm{m}$ diam., ramificado, septado, hialino; micélio externo ausente; ascocarpo ascostromático, subesférico, localizado no caule da planta, erumpente, $75,0-160 \times 120-425 \mu \mathrm{m}$, conectado ao hospedeiro através de um hipostroma, 99,0 - 148 x $100-198$ $\mu \mathrm{m}$, de deiscência por ruptura. Filamentos interteciais ausentes. Ascas bitunicadas, isoladas, espalhadas pelo interior do estroma, de formato inicialmente esférico (quando a exotúnica está intacta) passando a cilíndrico (após a ruptura da exotúnica e expansão da endotúnica), $25-45 \times 15-35 \mu \mathrm{m}$, com 8 ascósporos por asca (Fig. 1B-C). Ascósporos com septação transversal e longitudinal, 15,5-27,0 x 7,5-10,5 $\mu \mathrm{m}$, possuindo 1-4 septos longitudinais e 1-2 transversais, de coloração hialina a marrom clara, superfície lisa, embebidos em matriz mucilaginosa
(VIC 27795). As características morfológicas permitiram a identificação do fungo como sendo Diplotheca tunae (Spreng. ex Fr.) Starb., espécie monotípica, exclusiva da América do Sul, relatada como fitopatógeno somente em espécies da família Cactaceae (von Arx, Persoonia 2: 421. 1963; von Arx \& Müller, Studies in Mycology n.9. 1975). Relatos na literatura citam a ocorrência de D. tunae apenas em: Cereus macrogonus Salm-Dyck, Cereus variabilis Pfeiff., Opuntia inamoena K. Schum e Rhipsalis trigona Pfeiff. (Viégas, Índice de fungos da América do Sul. 1961). Portanto, esse é o primeiro relato desse fitopatógeno na espécie E. phyllanthus.

Agradecimentos ao $\mathrm{CNPq}$ pelo apoio financeiro e ao Parque Estadual do Rio Doce pelas facilidades de acomodação.

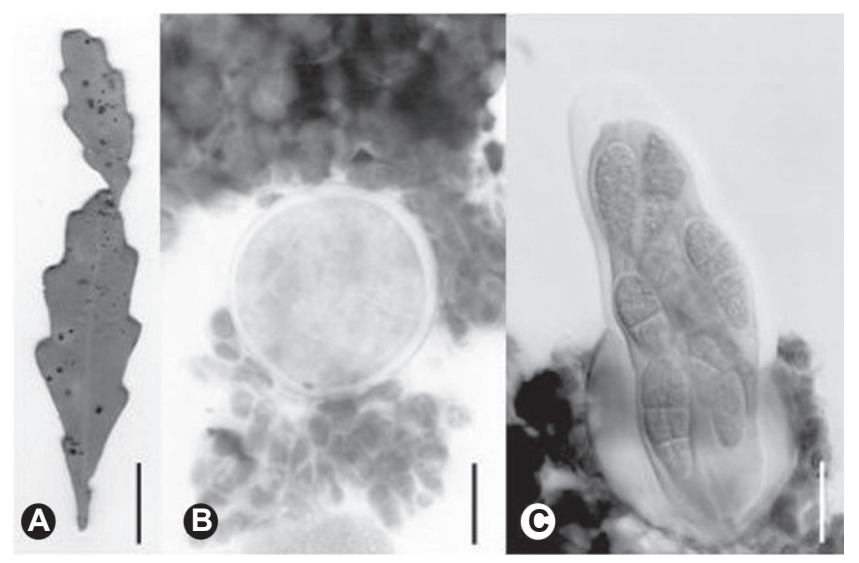

FIG. 1 - Diplotheca tunae. A. sintoma de verrugose negra em caule de Epiphyllum phyllanthus; B. asca bitunicada de formato esférico e C. liberação da endotúnica cilíndrica (após rompimento da exotúnica esférica), com ascósporos dictiosporos embebidos em matriz mucilaginosa. Barras: $(A)=3,0 \mathrm{~cm}$ e $(B$ e $C)=15 \mu \mathrm{m}$. 